\title{
The Effects of Albumin Level and Management of Fluid Replacement on Postoperative Period in Cardiac Surgery
}

Etik Kurul Onayı: Özel Șișli Kolan International Hospital Hastanesi, Etik Kurul onayı alınmıştır (01.10.2019)

Çıkar çatışması: Çıkar çatışması yoktur.

Hasta onamı: Bütün hastalardan ameliyat öncesi aydınlatılmış onam formu alınmıştır.
Ethics Committee Approval: Ethics Committee approval of Șişli Kolan International Hospital (01.10.2019)

Conflict of interest: There is no conflict of interest.

Informed consent: Informed consent forms were obtained from all patients before surgery.

Cite as: Tanrıkulu N, Özbek B, Demirsoy E. Kalp cerrahisinde albümin değerinin ve sıvı replasman yönetiminin postoperatif döneme etkisi. GKDA Derg. 2019;25(4):242-6.

öz

Amaç: Kalp cerrahisi sonrası sıvı replasmanında ilk tercih olarak kristalloidler önerilmekle birlikte, bazı özel durumlarda albümin ve sentetik kolloidler de kullanılabilmektedir. Bu çalışmada preoperatif albümin değerinin postoperatif döneme etkisi ve bu hastalarda albümin kullanımının sonuca etkileri araştırıldı.

Yöntem: Servisimizde 01.01.2014-31.12.2018 tarihleri arasında açık kalp cerrahisi uygulanan hastalar retrospektif olarak incelendi. Hastalar preoperatif albümin değerlerine göre 2 gruba ayrıldı. Preoperatif albümin değeri $4 \mathrm{~g} / \mathrm{dL}$ olan hastalar Grup 1'i, albümin değeri $4 \mathrm{~g} / \mathrm{dL}$ üzerinde olan hastalar Grup 2'yi oluşturdu. Hastalarda preoperatif albümin değerinin postoperatif erken dönem morbidite ve mortaliteye etkileri ve kullanılan sıvı replasmanı ile ilişkisi değerlendirildi.

Bulgular: Preoperatif albümin değeri düsük olan hastalarda postoperatif dönemde de hipoalbüminemi devam etti. Takiplerde 13 hastada minör komplikasyon gelişirken bunun 12'si Grup 1'de olup, 10 hastaya albümin replasmanı uygulanmıştı. Postoperatif dönemde 9'u Grup 1'de olmak üzere 10 mortali geliști. Kaybedilen hastaların 7'sine postoperatif dönemde albümin replasmanı yapılmasına rağmen, hastalar kaybedilmişti. Preoperatif albümin değerinin $4 \mathrm{~g} / \mathrm{dL}$ altında olmasının postoperatif komplikasyon riskini 14 kat arttırdığı ve bu hastalarda albümin replasmanı uygulanmasının sonuca beklenen katkıyı sağlamadığı görüldü.

Sonuç: Preoperatif albümin değerinün düš̈klüğü postoperatif dönemde artmış morbidite ve mortalite ile ilişkili olmakla birlikte, albümin replasmanı sonuca olumlu katkı sağlamamaktadır. Güncel kılavuzların önerisi doğrultusunda kalp cerrahisi sonrası sıvı replasmanında kan replasmanı gerekmeyen durumlarda, kristalloid solüsyonunun ilk tercih olarak düşünülmesi doğru olacaktır.

Anahtar kelimeler: albümin, kalp cerrahisi, kolloid, kristalloid, onkotik basınc

ABSTRACT

Objective: Although crystalloid solutions are recommended as first choice for fluid replacement after cardiac surgery, abumin and synthetic colloids are used in special condition. In this study, the effects of preoperative albumin level on postoperative period and the effects of albumin on outcomes were investigated.

Method: Patients who underwent cardaic surgery between 01.01.2014 and 12.31.2018 were evaluated retrospectively. Patients were divided into two groups according to preoperative albumin levels. Patients with preoperative albumin levels $<4 \mathrm{~g} / \mathrm{dL}$ and $\geq 4 \mathrm{~g} / \mathrm{dL}$ constituted Groups 1 , and 2 respectively. Effects of preoperative albumin levels on early postoperative morbidity and mortality and its relationship with fluid replacement were evaluated.

Results: Hypoalbuminemia persisted also during the postoperative period in patients with low preoperative albumin levels. During follow-up, 13 patients developed minor complications, of which 12 were in Group 1, and 10 had albumin replacement. Although 7 patients underwent albumin replacement 9 patients in Group 1, and 1 patient in Group 2 exited during postoperative period It was seen that preoperative albumin value under $4 \mathrm{~g} / \mathrm{dL}$ increased the risk of postoperative complications 14 times and the application of albumin replacement in these patients did not provide the expected contribution to the outcome.

Conclusion: Although low preoperative albumin value is associated with increased morbidity and mortality during the postoperative period, albumin replacement does not contribute positively to the outcome. In accordance with the recommendations of current guidelines, it would be appropriate to consider crystalloid solution as the first choice in cases where blood replacement is not required after cardiac surgery.
Alındığı tarih: 18.07 .2019

Kabul tarihi: 16.10 .2019

Yayın tarihi: 31.12 .2019

Nurşen Tanrıkulu Kolan International Hospital Anestezi Servisi

İstanbul - Türkiye

nursentanrikulu1@gmail.com ORCID: 0000-0003-3601-1468

B. Özbek 0000-0002-3671-2128

Van Eğitim ve Araştırma Hastanesi Kalp Damar Cerrahisi Servisi Van - Türkiye

C. Ceylan 0000-0002-7004-4530 Kolan International Hospital Anestezi Servisi istanbul - Türkiye

Keywords: albumin, cardiac surgery, colloid, crystalloid, oncotic pressure

(C) Telif hakkı Göğüs Kalp Damar Anestezi ve Yoğun Bakım Derneği'ne aittir. Logos Tıp Yayıncılık tarafindan yayınlanmaktadır Bu dergide yayınlanan bütün makaleler Creative Commons Atff-Gayri Ticari 4.0 Uluslararası Lisansı ile lisanslanmıştı. 


\section{Giriş}

Kalp cerrahisinde kardiyopulmoner baypasın etkisi ile artmış kapilller geçirgenlik sıvı fizyolojisini ve hastaların sıvıya yanıtını değiştirir. Perioperatif dönemde azalmış onkotik basınç, inflamasyon ve endotel hasarı intersitisyel alana sıvı kaçışına neden olur ${ }^{[1]}$. Ameliyattaki kan ve sıvı kaybına ek olarak intersitisyel alana sıvı akışı hipovolemi ile sonuçlanır ${ }^{[1]}$.

Kalp cerrahisi sonrası sıvı replasmanında kristalloid solusyonlar, albümin, sentetik kolloidler ve taze donmuş plazma kullanılabilir. Avrupa'da sıvı replasmanında ilk tercih kristalloidler iken, daha sonra ise jelatinler, sentetik kolloidler ve albümin kullanilır. $A B D$ 'de ise yine ilk tercih kristalloid olmasına rağmen, jelatinler kullanılmadığından sentetik kolloid olarak tek tercih albümindir ${ }^{[1]}$. Sentetik kolloidlerin kritik hastalarda kullanımının FDA tarafından uyarılmasının ardından sentetik kolloidlerin klinik kullanımı \%10'un altına düşmüştür.

Günümüzde kalp cerrahisi sonrası volüm gereksiniminde kanama yoksa kristalloidler ilk tercih olarak kullanılmaktadır. Transfüzyon gerektirmeyen kan kaybı, ekstrakorporal membran oksijenatörü (ECMO) ve ventriküler destek cihazı (VAD) kullanıldığında gelişen volüm gereksiniminde $\% 5$ albümin ilk tercih olabilir ${ }^{[1]}$. Bu çalışmada, kalp cerrahisinde preoperatif albümin değerlerinin postperatif döneme etkisi ve albümin kullanımının morbidite ve mortalite üzerine etkisi araştırıldı.

\section{GEREÇ ve YÖNTEM}

Servisimizde 01.01.2014-31.12.2018 tarihleri arasında açık kalp cerrahisi uygulanan hastalar retrospektif olarak incelendi. Hastaların demografik bilgileri, uygulanan cerrahi prosedür ve labarotuvar bulgularına ait veriler hasta dosyalarından elde edildi. Bütün hastalardan ameliyat öncesi aydınlatılmış onam formu alınmıştı. Hastalar preoperatif albümin değerlerine göre 2 gruba ayrıldı. Preoperatif albümin değeri $4 \mathrm{~g} / \mathrm{dL}$ ve altında olan hastalar Grup 1, albümin değeri $4 \mathrm{~g} / \mathrm{dL}$ üzerinde olan hastalar Grup 2'yi oluşturdu. Hastaların postoperatif erken dönem morbidite ve mortalite oranları incelenerek preoperatif albümin değeri ile ilişkisi incelendi. Ayrıca bu hastalarda kullanılan sıvı replasmanı değerlendirilerek albümin kullanımının sonuca etkileri araştırıldı.

İstatistiksel analiz IBM SPSS 24.0, SPSS Inc, Chicago, IL programı kullanılarak yapıldı. Kategorik değişkenler frekans ve yüzde olarak, devamlı değişkenler ortalama ve standart sapma olarak yazıldı. Her 2 grubun istatistiksel karşılaştırılması yapılırken, kategorik değişkenler için ki-kare testi ve Fisher's exact test; sürekli değişkenler için two sample t-test or Wilcoxon rank sum test kullanıldı.

\section{BULGULAR}

Çalışma periyodunda servisimizde açık kalp cerrahisi uygulanan ve preoperatif albümin değerlerine ulaşıIan 242 hasta çalışmaya dâhil edildi. Hastaların 126'sı Grup 1 ve 116'sı Grup 2'de yer almakta olup, hastalara ait demografik veriler Tablo 1'de gösterilmiştir.

Bütün hastalar standart yöntemler ile ameliyat edilmişti. Hastaların 198'i (\%82) koroner baypas ameliyatı olmuştu, diğerlerine ise eşlik eden kapak cerrahisi ya da yalnızca kapak cerrahisi uygulanmıştı. Grup 1'de eritrosit replasmanı ve albümin replasmanı istatistiksel olarak anlamlı derecede yüksekti (Tablo 2).

Preoperatif albümin değeri düşük olan hastaların postoperatif takiplerinde de albümin değerleri anlamlı derecede düşük idi. Postoperatif dönemde 10 hasta kaybedildi. On mortalitenin 9'u Grup 1'de idi. Kaybedilen hastaların 7'sine postoperatif dönemde albümin replasmanı yapılmasına rağmen, hastalar kaybedilmişti. Grup 2'de 1 hastada safen yara yerinde infeksiyon gelişirken, Grup 1'de 12 hastada plevral efüzyon, 1 hastada batın komplikasyonu, 1 hastada diyaliz gereksinimi, 2 hastada mediastinit ve 1 hastada safen yara yerinde infeksiyon gelişmişti. Postoperatif komplikasyon gelişen hastaların onunda albümin replasmanı uygulanmıştı (Tablo 3 ). 
Tablo 1. Preoperatif değişkenler.

\begin{tabular}{lccc} 
& Grup 1 (n=126) & Grup 2 (n=116) & p değeri \\
\hline Yaş (yıl) & & & 0.02 \\
Cinsiyet (K / E) & $62.3 \pm 11$ & $59.1 \pm 10.5$ & 0.03 \\
Kilo (kg) & $45 / 81$ & $27 / 89$ & 0.48 \\
Boy (cm) & $79.7 \pm 13.4$ & $80 . .9 \pm 13.2$ & 0.04 \\
Diabetes mellitus (n) & $165.4 \pm 9$ & $167.8 \pm 9.7$ & 0.1 \\
Hipertansiyon (n) & 62 & 45 & 0.7 \\
Sigara & 65 & 57 & 0.19 \\
Kronik böbrek yetmezliği (n) & 20 & 26 & 0.01 \\
Kronik obstrüktif akciğer hastalığı (n) & 12 & 2 & $<0.001$ \\
Karotis arter hastalığı (n) & 27 & 8 & 0.28 \\
Periferik arter hastalığı & 11 & 6 & 0.66 \\
Ejeksiyon fraksiyonu (\%) & 7 & 8 & $<0.001$ \\
Mean PAP (mmHg) & $51.4 \pm 9.7$ & $55.1 \pm 8.9$ & 0.04 \\
Serum kreatinin (mg/dl) & $31.2 \pm 13$ & $28 \pm 11.5$ & $0.9 \pm 0.3$ \\
Preoperatif AST (mg/dl) & $1 \pm 0.6$ & $28.3 \pm 22.1$ & 0.15 \\
Preoperatif ALT (mg/dl) & $33.1 \pm 29.3$ & $24.3 \pm 16.2$ & 0.43 \\
Preoperatif albümin (g/dl) & $26 \pm 15.8$ & $4.29 \pm 0.2$ & $<0.001$ \\
& $3.48 \pm 0.5$ & & \\
\hline
\end{tabular}

\section{Tablo 2. Operatif verilerin karşılaştırııması.}

\begin{tabular}{lccc} 
& Grup 1 ( $\mathbf{n = 1 2 6 )}$ & Grup 2 (n=116) & p değeri \\
\hline Kros klemp süresi (dk.) & $68.7 \pm 32$ & $65.5 \pm 28.7$ & 0.41 \\
KPB süresi (dk.) & $112.7 \pm 42.3$ & $104.8 \pm 36.5$ & 0.12 \\
Postoperatif AF (n) & 76 & 85 & 0.04 \\
Eritrosit replasmanı (n) & 3.4 & 2 & $<0.001$ \\
Taze donmuş plazma replasmanı (n) & 1.3 & 1 & 0.13 \\
Albümin replasmanı (n) & 63 & 8 & $<0.001$ \\
\hline
\end{tabular}

$A F=$ Atrial fibrilasyon; $K P B=$ Kardiyopulmoner baypas

Tablo 3. Postoperatif verilerin karşılaştırılması.

\begin{tabular}{lccc} 
& Grup 1 $(\mathbf{n = 1 2 6 )}$ & Grup 2 (n=116) & p değeri \\
\hline Postoperatif 1. gün kreatinin (mg/dL) & $1.2 \pm 0.8$ & $1 \pm 0.3$ & 0.01 \\
Postoperatif 1. gün AST (mg/dL) & $117.9 \pm 454.6$ & $53.1 \pm 28.5$ & 0.11 \\
Postoperatif 1. gün ALT (mg/dL) & $74.2 \pm 460.7$ & $24.6 \pm 14.9$ & 0.25 \\
Postoperatif 1. gün albümin (mg/dL) & $2.94 \pm 0.42$ & $3.26 \pm 0.35$ & $<0.001$ \\
Postoperatif 5. gün kreatinin (mg/dL) & $1.1 \pm 0.7$ & $0.9 \pm 0.3$ & 0.01 \\
Postoperatif 5. gün AST (mg/dL) & $147.3 \pm 1046$ & $34.35 \pm 19.8$ & 0.23 \\
Postoperatif 5. gün ALT (mg/dL) & $81.9 \pm 433.4$ & $22.4 \pm 15$ & 0.13 \\
Postoperatif 5. gün albümin (mg/dL) & $3.21 \pm 0.42$ & $3.32 \pm 0.27$ & 0.02 \\
Infeksiyon (n) & 40 & 28 & 0.18 \\
Yoğun bakım kalış süresi (gün) & 3.1 & 1.5 & $<0.001$ \\
Hastane kalış süresi (gün) & 9.7 & 7.7 & $<0.001$ \\
Reoperasyon (n) & 4 & 1 & 0.21 \\
Morbidite & 17 & 1 & $<0.001$ \\
Mortalite $(\mathrm{n})$ & 9 & 1 & $<0.001$ \\
\hline
\end{tabular}

Preoperatif albümin değeri ile postoperatif morbidite ve mortalite karşılaştırıldığında albümin değerinin
$4 \mathrm{~g} / \mathrm{dL}$ altında olmasının postoperatif komplikasyon riskini 14 kat arttırdığı belirlendi (Tablo 4). 
Tablo 4. Albüminin postoperatif komplikasyon üzerine etkisi.

95\% C.I.for $\operatorname{EXP(B)}$

\begin{tabular}{lcccccccc} 
& B & S.E. & Wald & df & Sig. & Exp(B) & Lower & Upper \\
\hline Albümin & 2.696 & .746 & 13.044 & 1 & .000 & 14.820 & 3.431 & 64.011 \\
Constant & -4.043 & .713 & 32.129 & 1 & .000 & .018 & & \\
\hline
\end{tabular}

$A F=$ Atrial fibrilasyon; $K P B=$ Kardiyopulmoner baypas

\section{TARTIŞMA}

Kalp cerrahisinde preoperatif dönemdeki düşük albümin değeri atmış mortalite ve morbidite ile ilişkilidir ${ }^{[2]}$. Preoperatif albümin düşüklüğü koroner arter stent işlemi sonrasında bile artmış mortalite ve morbidite ile ilişkili bulunmuştur ${ }^{[3]}$. Bu hastalara postoperatif dönemde albümin replasmanının yararlı olduğu ya da bir etkisinin olmadığı konusunda farklı görüşler mevcuttur ${ }^{[4-6]}$. İki yüz kırk iki hastayı incelediğimiz bu çalışmada, preoperatif dönemde hipoalbüminemi morbidite ve mortalite açısından bir risk faktörü olarak bulunmuş olmasına rağmen; albümin replasmanının olumlu katkısı saptanmamıştır.

Hipoalbüminemi sistemik inflamasyonun yanı sıra karaciğer ve böbrek disfonksiyonunu ve malnütrisyonu yansıtır ${ }^{[5]}$. Düşük serum albümin değeri akut faz yanıtına ve inflamasyona bağlı olarak prognozu olumsuz etkiler ${ }^{[7]}$. Koroner arter baypas greft (KABG) operasyonu sonrası gelişen sıvı gereksiniminde albümin kullanımının mortaliteyi azalttığını bildiren yayınlar mevcuttur ${ }^{[4]}$. Hipoalbüminemi renal replasman tedavisi gereksinimi için çok güçlü bir prediktör olarak bulunmuş olup, renal replasman tedavisi gereksiniminin ise artmış morbidite ile ilişkili olduğu bildirilmiştir ${ }^{[5]}$. Yaklaşık 2.000 hastanın incelendiği kohort çalışmasında ise \%5 albümin solüsyonunun 30 gün içinde hastaneye yine başvuru oranlarını anlamlı derecede düşürdüğü, buna karşın morbidite ve akut böbrek yetmezliği üzerine etkisi olmadığı bildirilmiştir ${ }^{[6]}$.

Genel yoğun bakımlarda albümin replasmanının kristalloid sıvıya tercih edilmesinin mortaliteye önemli bir katkısı bulunmamıştır. Fakat kalp cerrahisinde durum biraz daha farklıdır. İnflamatuar yanıta bağlı gelişen vazodilatasyon ve bundan kaynaklı hipotansiyon tedavisinde önyükü ve kardiyak outputu arttırmak için sıvı replasmanı gerekir. Bu durumda kristalloidler kullanılabildiği gibi farklı kolloidler de kullanılabilir. Sıvı replasman sırasında yalnızca kristalloid verildiğinde daha fazla miktarda sıvı verilir. Kolloidlerle kristalloid karışımı verilmesi daha az sıvı verilerek volum ekspansiyonunu sağlayabilir ${ }^{[1]}$. Hiperonkotik albümin kullanımı, hipoonkotik kolloidlerle karşılaştırıldığında renal yetmezlik gelişimi ve mortalite ile ilişkili olabilir ${ }^{[8]}$. Öte yandan preoperatif albümin değeri $4 \mathrm{~g} / \mathrm{dL}$ 'nin altında olan hastalarda albümin replasmanının evre 1 akut böbrek yetmezliği riskini azalttığıni bildiren yayınlar da mevcuttur ${ }^{[9]}$.

Rabin ve ark. ${ }^{[4]}$ yaklaşık 20.000 hastanın retrospektif incelemesinde KABG sonrası volum replasmanında albümin kullanılmasının mortaliteyi \%25 azalttığını bildirmiştir. Kalp cerrahisi sonrası sıvı replasmanı ile ilgili 17.000 hastanın incelendiği bir başka çalışmada, hidroksietil nişasta (HES), human albümin ve kristallloid kullanımın etkileri postoperatif 6 aylık dönemde karşılaştırılmıştır. Bu çalışmada, HES kullanımı ile kristalloid karşılaştırıldığında HES kullanımının mortalite, diyaliz gereksinimi olan renal yetmezlik ve iskemik olay üzerine etkisi saptanmamıştır. Human albümin kullanımı kristalloid ile karşılaştırıldığında mortalite, diyaliz gereksinimi olan renal yetmezlik ve iskemik olay; HES kullanımı ile karşılaştırıldığında diyaliz gereksinimi olan renal yetmezlik açısından riskli bulunmuştur ${ }^{[8]}$.

Ameliyat sonrası dönemde kanama, vazodilatasyon ya da kapiller kaçağa bağlı olarak sıvı kaybı gelişir. Kapiller kaçak durumunda kolloid yerine kristalloid 
uygulandığında daha fazla sıvı perfüzyonu gerekir ve bu durum akciğer ödemine neden olabilir ${ }^{[4]}$. Kalp cerrahisi sonrası aşırı sıvı yüklenmesi yoğun bakım ve hastane kalış süresini arttıracağından kolloidler tercih edilebilir ${ }^{[4]}$. Fakat yüksek maliyeti nedeni ile yoğun bakım ünitesinde albümin kullanımı farklı ülkelerdeki sosyal güvenlik kurumu tarafından belirli prosedürlerle kısıtlanmıştır. Maliyetten kaçınmak için kolloid kısıtlandığında kristalloidden kaynaklanan sıvı yüklenmesi hastane ya da yoğun bakım kalış süresini ve dolayısıyla maliyeti arttırmaktadır. Bu nedenle hastanın gereksiniminin belirlenerek en uygun SIVı replasmanının uygulanması en doğru yöntem olacaktır.

Rabin ve ark. ${ }^{[4]} 2015$ yılında albümin uygulamasının erken postoperatif periyotta 3 It'den fazla sıvı gereksinimi, hipoalbüminemi $(<3 \mathrm{~g} / \mathrm{dL})$ ve sIVı yüklenmesi durumu ile kısıtlanmasından sonra takiplerde morbidite ve mortalite oranlarında fark olmadığını fakat ayda 45.000 dolardan fazla tasarruf sağlandığını bildirmiştir ${ }^{[4]}$.

Hipoalbüminemi kalp cerrahisi için artmış morbidite ve mortalite için bir risk faktörüdür. Kalp cerrahisi sonrası postoperatif dönemde artan inflamasyon ve vazodilatasyona bağlı gelişen hipovoleminin yönetiminde, hastada sıvı yüklenmesine neden vermeden kristalloid replasmanı, klinik gereksinimine göre kolloidlerin verilmesi postoperatif takiplere olumlu katkı sağlayacaktır.

\section{KAYNAKLAR}

1. Aronson $S$, Nisbet $P$, Bunke $M$. Fluid resuscitation practices in cardiac surgery patients in the USA: a survey of health careproviders. Perioper Med (Lond). 2017;19:15. https://doi.org/10.1186/s13741-017-0071-6

2. Kawahito K, Aizawa K, Oki S, Saito T, Misawa Y. Heart valve surgery in hemodialysis-dependent patients: nutrition status impact on surgical outcome. J Artif Organs. 2016;19:134-40. https://doi.org/10.1007/s10047-015-0883-4

3. Wada H, Dohi T, Miyauchi K, Shitara J, Endo H, Doi S et al. Long-term clinical impact of serum albumin in coronary artery disease patients with preservedrenal function.Nutr Metab Cardiovasc Dis. 2018;28:285-90. https://doi.org/10.1016/j.numecd.2017.11.005

4. Rabin J, Meyenburg T, Lowery AV, Rouse M, Gammie JS, Herr D. Restricted Albumin Utilization Is Safe and Cost Effective in a Cardiac Surgery Intensive Care Unit. Ann Thorac Surg. 2017;104:42-8. https://doi.org/10.1016/j.athoracsur.2016.10.018

5. Kato TS, Machida Y, Kuwaki K, Yamamoto T, Amano A. Factors associated with postoperative requirement of renal replacement therapy following off-pump coronary bypass surgery. Heart Vessels. 2017;32:134-42. https://doi.org/10.1007/s00380-016-0855-5

6. Kingeter $\mathrm{AJ}$, Raghunathan $\mathrm{K}$, Munson $\mathrm{SH}$, Hayashida DK, Zhang $X$, lyengar $S$ et al. Association between albumin administration and survival in cardiac surgery: a retrospectivecohort study. Can J Anaesth. 2018;65(11): 1218-27. https://doi.org/10.1007/s12630-018-1181-4

7. Kurumisawa S, Kawahito K. Risk analysis using the prognostic nutritional index in hemodialysis-dependent patientsundergoing cardiac surgery. J Artif Organs. 2018;21(4):443-9. https://doi.org/10.1007/s10047-018-1056-z

8. Ryhammer PK, Tang M, Hoffmann-Petersen J, Leonaviciute D, Greisen J, Storebjerg Gissel M et al. Colloids in Cardiac Surgery-Friend or Foe? J Cardiothorac Vasc Anesth. 2017;31:1639-48. https://doi.org/10.1053/j.jvca.2017.02.001

9. Lee EH, Kim WJ, Kim JY, Chin JH, Choi DK, Sim JY et al. Effect of Exogenous Albumin on the Incidence of Postoperative Acute Kidney Injury in Patients Undergoing Off-pump Coronary Artery Bypass Surgery with a Preoperative Albumin Level of Less Than $4.0 \mathrm{~g} / \mathrm{dl}$. Anesthesiology. 2016;124:1001-11. https://doi.org/10.1097/ALN.0000000000001051 